\title{
Proximodistal Segregation of Nonspatial Information in CA3: Preferential Recruitment of a Proximal CA3-Distal CA1 Network in Nonspatial Recognition Memory
}

\author{
Nozomu H. Nakamura, ${ }^{1}$ Vera Flasbeck, ${ }^{1}$ Nicolas Maingret, ${ }^{1}$ Takashi Kitsukawa, ${ }^{2}$ and Magdalena M. Sauvage ${ }^{1}$ \\ ${ }^{1}$ Functional Architecture of Memory Unit, Mercator Research Group, Faculty of Medicine, Ruhr University Bochum, Bochum 44801, Germany, and \\ ${ }^{2}$ Graduate School of Frontier Biosciences, Osaka University, Suita, Osaka 565-0871, Japan
}

\begin{abstract}
A prevailing view in memory research is that $\mathrm{CA} 3$ principally supports spatial processes. However, few studies have investigated the contribution of CA3 to nonspatial memory function. Interestingly, the proximal part of CA3 (close to the dentate gyrus) predominantly projects to distal CA1 (away from the dentate gyrus), which preferentially processes nonspatial information. Moreover, the cytoarchitecture and connectivity patterns in the proximal and distal parts of CA3 strongly differ, suggesting a functional segregation in this area. Here, we tested whether CA3 is recruited during nonspatial recognition memory, and whether nonspatial information is differentially represented along the proximodistal axis of CA3. Furthermore, we investigated whether the pattern of activation within CA3 would mirror that of CA1. We used a high-resolution imaging technique specifically designed to analyze brain activity in distant areas that is based on the detection of the expression of the immediate-early gene $A r c$, used as a marker of neuronal activation. We showed that proximal CA3 is strongly recruited during a nonspatial delayed nonmatching-to-sample recognition memory task in rats, while distal CA3 is not. In addition, distal CA1 was more activated than proximal CA1 in the same task. These findings suggest a functional segregation of CA3 that mirrors that of CA1, and potentially indicate the existence of a proximal CA3-distal CA1 hippocampal subnetwork that would preferentially process nonspatial information during recognition memory.
\end{abstract}

\section{Introduction}

Many studies have reported the critical role of CA3 in the rapid learning of new spatial and contextual information (for reviews, see Rolls, 2007; Kesner, 2007). In contrast, little is known about its contribution to nonspatial memory. However, CA3 contributes to trace eye-blinking conditioning (Kishimoto et al., 2006; Thompson et al., 1996), and lesions of CA3 impair the memory for pairs of items (Farovik et al., 2010). Interestingly, lesions at different locations of CA3 do not affect memory performance to the same extent. For example, lesions of CA3 close to the dentate gyrus (DG) impair performance on a task combining spatial and object information to a larger extent than lesions close to CA2 (Hunsaker et al., 2008). Altogether, these studies suggest that CA3 could also play a fundamental role in nonspatial memory, possibly via a segregation of spatial and nonspatial information along its proximodistal axis. This hypothesis is further supported by a vast number of anatomical studies (for review, see Witter, 2007). For example, a genome-scale study detecting $>20,000$

\footnotetext{
Received Sept. 19, 2012; revised May 15, 2013; accepted May 30, 2013.

Author contributions: M.M.S. designed research; N.H.N., V.F., and N.M. performed research; T.K. contributed unpublished reagents/analytic tools; N.H.N., T.K., and M.M.S. analyzed data; N.H.N. and M.M.S. wrote the paper.

This work was supported by the Mercator Stiftung and the FORUM Grant F699-10. We also thank Dr. Lars Leichert for assistance with technical support, and Zachery Beer for editing.

The authors declare no competing financial interests.

Correspondence should be addressed to Magdalena Sauvage, MRG1/FAM Unit, Medicine Faculty, Ruhr University Bochum, Universitaetstrasse 150, 44801 Bochum, Germany. E-mail: magdalena.sauvage@rub.de.

DOI:10.1523/JNEUROSCI.4480-12.2013

Copyright $\odot 2013$ the authors $\quad 0270-6474 / 13 / 3311506-09 \$ 15.00 / 0$
}

genes in CA3 reported distinct expression domains that could underlie a functional segregation along its proximodistal and septotemporal axes (Thompson et al., 2008). The pattern of connectivity of proximal CA3 (close to the DG) and distal CA3 (close to CA2) is quite different. Of special interest, proximal CA3 receives little direct input from the entorhinal cortex (EC) because the lacunosum moleculare layer is virtually absent there ( $\mathrm{Li}$ et al., 1994; Ishizuka et al., 1995). In addition, proximal CA3 primarily receives projections from the exposed blade of the DG (Claiborne et al., 1986), which is not recruited during exposure to spatial contexts, as reported in an immediate-early gene (IEG) imaging study (Chawla et al., 2005). In contrast, the enclosed blade of the DG, which preferentially projects to distal CA3 (Claiborne et al., 1986), was strongly recruited in the same Arc study (Chawla et al., 2005). Furthermore, proximal CA3 preferentially projects to distal CA1 (close to the subiculum), whereas distal CA3 primarily projects to proximal CA1 (close to CA2; Amaral and Witter, 1989; Ishizuka et al., 1990; Li et al., 1994). Last, studies based on tract tracing, electrophysiological recordings, and IEG expression have recently reported that distal CA1 preferentially processes nonspatial information provided by the lateral EC, while proximal CA1 processes spatial information provided by medial EC inputs (Tamamaki and Nojyo, 1995; Suzuki et al., 1997, Young et al., 1997; Naber et al., 2001; Fyhn et al., 2004; Hargreaves et al., 2005; Henriksen et al., 2010; Burke et al., 2011, Deshmukh and Knierim, 2011; Ito and Schuman, 2012).Together, these studies suggest that proximal CA3 could be more involved in the processing of nonspatial information than its distal part, and that 


\section{A Study phase} (10 odors, one at a time)

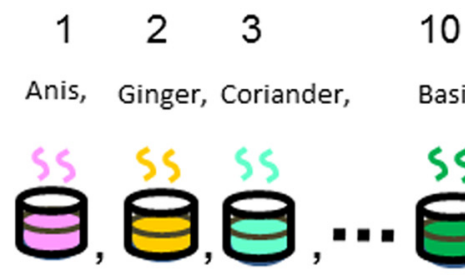

\section{Recognition phase}

(10 'old' and 10 'new' odors)

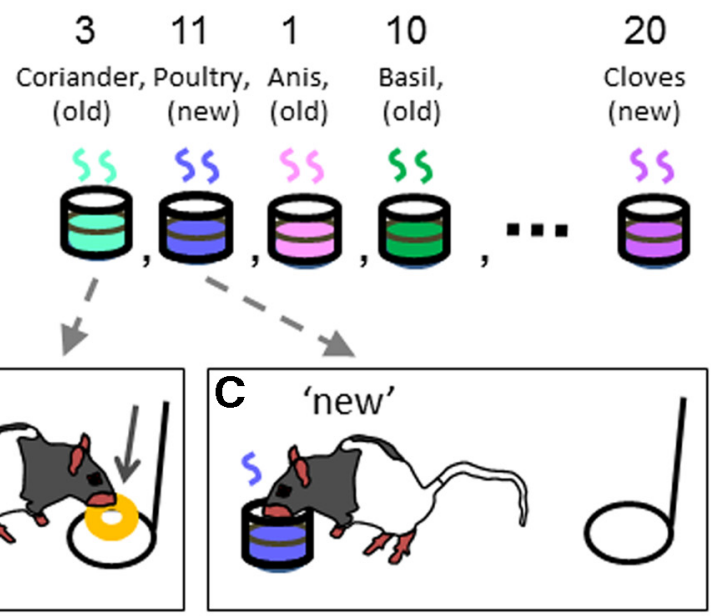

D
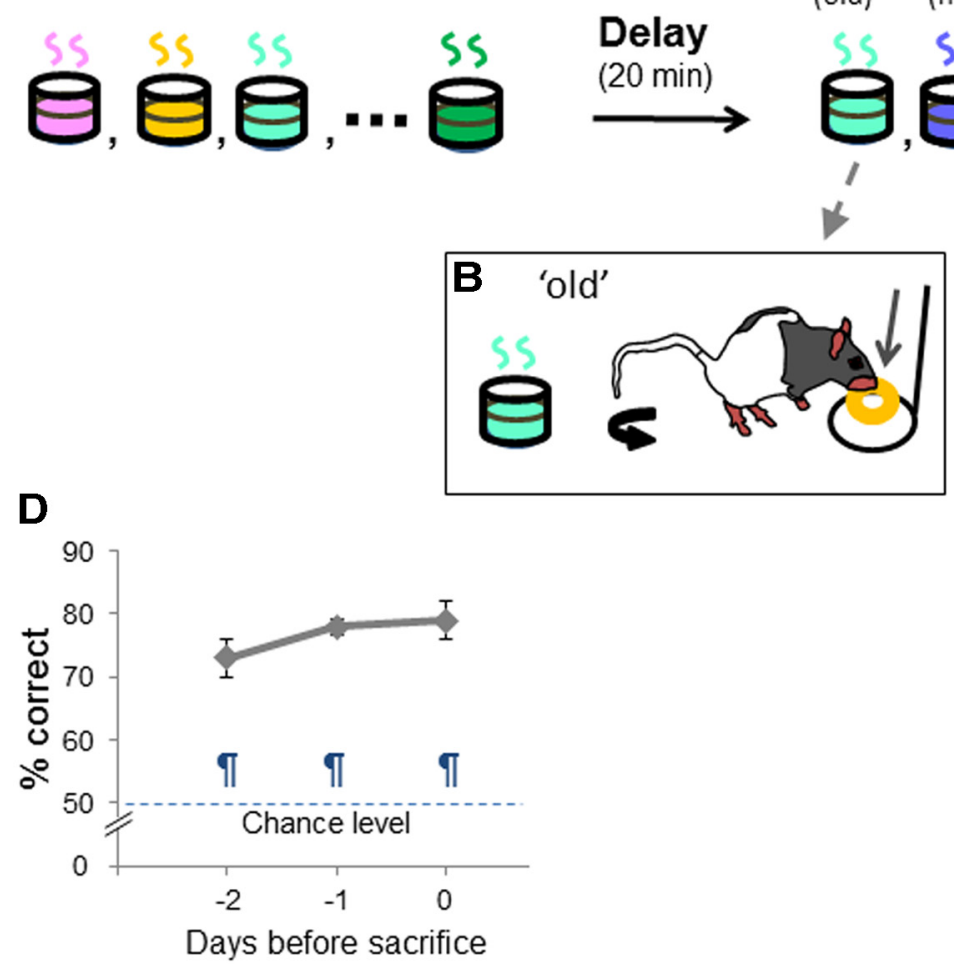

Figure 1. Non spatial recognition memory task. $\boldsymbol{A}$, Ten odors are presented to the animal during the study phase (one at a time). After a 20 min delay, the memory for the studied odors is tested by presenting the same odors intermixed with 10 new odors to the animals (also one at a time). $\boldsymbol{B}, \boldsymbol{C}$, Delayed nonmatching-to-sample rule. If the odor belonged to the study list (old odor), the rat was expected to refrain digging and turn around to get a food reward at the back of the cage $(\boldsymbol{B})$. If the odor did not belong to the study list (new odor), the rat could dig in the stimulus cup to retrieve a buried reward (C. D, The percentage of correct choices (accuracy; means \pm SEM) is shown for the last three sessions of testing. Comparison to chance level (50\% correct): " $p<0.005$.

distal CA1 would be more activated than proximal CA1 during nonspatial memory. Because of the folding of the hippocampus, the dorsoventral and mediolateral coordinates of the proximal and distal parts of CA3 and CA1 vary greatly along the transverse axis, rendering a lesion/inactivation approach unlikely to yield the spatial resolution necessary to tease apart the specific function of the proximal or distal parts of CA1 and CA3. For this reason, we used a high-resolution imaging technique (e.g., to the cellular level) based on the detection of the expression of the IEG Arc in the brain, and studied patterns of neuronal activation during a delayed nonmatching-to-sample (DNMS) recognition memory task based on odors (for review, see Guzowski et al., 2005; Sauvage, 2010).

\section{Materials and Methods}

Subjects and stimuli. Adult male Long-Evans rats [300-350 g; $n=18$ in total; $n=5$ DNMS animals, $n=5$ "random reward" animals, $n=4$ controls; and $n=4$ maximal electroconvulsive seizures (MECS) animals] were maintained under reverse light/dark cycle (7:00 A.M. light off/7:00 P.M. light on) at a minimum of $90 \%$ of normal body weight, handled a week before the experiment, and tested in their home cage. The stimulus odors were common household scents (thyme, paprika, coriander, etc.) mixed with playground sand. The scented sand was held in Nalgene plastic cups (one odor per cup), and a cup was fixed on a small platform lowered in the front part of the cage for testing. A pool of 40 household odors was available, 20 were used each day. All procedures were approved by the Ruhr University Bochum Institutional Animal Use Committee and the LANUV (8.87-51.04.20.09.323).

Behavioral paradigm. Behavioral training followed the training protocol previously described in the studies by Sauvage et al. $(2008,2010)$. In brief, to study nonspatial recognition memory, we used the innate ability of rats to dig and to discriminate between odors. Each training session contained a "study" phase, a delay, and a "recognition" phase (Fig. 1). Each day, rats were presented with a study list of 10 odors, which was different each day. Odors were chosen in a pseudo random manner. During the recognition phase, animals were tested for their ability to distinguish between the 10 odors presented to them during the study phase ("old" odors) and 10 additional odors ("new" odors) that were part of the pool of forty odors, but were not presented during the study phase (Fig. 1A). To do so, animals were first trained to dig in the stimulus cups with unscented sand to retrieve one $1 / 4$ of piece of Loop cereal (Kellogg's) after which they were trained on a DNMS rule. During the recognition phase, when rats were presented with an odor that was part of the study list (old odor), rats were required to refrain digging, turn around, and go to the back of the cage to receive a food reward: a correct response for an old odor (Fig. $1 B$; an incorrect response would be digging in the stimulus cup). Conversely, when the odor was not part of the study list (new odor), animals could retrieve a buried reward by digging in the test cup: a correct response for a new odor (Fig. $1 C$; an incorrect response would be going to the back of the cage to receive the reward). To ensure that the task could not be solved by smelling the reward buried in the sand, all cups were baited with a reward, but the reward was not accessible to the rats when an old odor was presented (e.g., trapped under a mesh). 
In addition, no spatial information useful to solve the task was available to the rats, given that testing cups for new and old odors were presented at the exact same location. Reward locations differed for the new and old odors (front and back of the cage, respectively), but were only experienced by the animals once a decision had been made (e.g., when the trial was over), hence could not contribute to behavioral performance. Training lasted $\sim 2$ months and consisted of several steps, during which the number of studied odors increased from one to 10 , the delay increased from one to $20 \mathrm{~min}$, and the number of odors during the recognition phase increased from 2-20 (half old, half new). Animals transitioned between successive training stages when performance reached a minimum of $75 \%$ correct for two consecutive days. Once this criterion was reached for the final training stage ( 10 study odors, 20 min delay, and 20 test odors), the DNMS animals $(n=5)$ were tested for one additional session and killed immediately after the end of the recognition phase, which lasted $\sim 8 \mathrm{~min}$. Each DNMS animal was paired with a control animal $(n=4)$, which was exposed to the same experimental conditions, but did not perform the task. Control animals were killed at the same time as their match. Furthermore, to ensure that the pattern of Arc expression was due to memory retrieval and not to testing conditions alone (such as stimulus presentation, motor demand, handling etc...), we also detected Arc pre-RNA in an additional "random reward" group $(n=5)$. The random reward group was subjected to the same testing conditions as the DNMS group, but the reward was randomly assigned to the stimulus cup for half of the trials or to the back of the cage for the other half of the trials (instead of following a DNMS rule), so that memory retrieval does not occur. Moreover, to determine whether the differential activation that we observe within CA 3 and CA1 could be due to a higher likelihood of $A r c$ to be expressed in proximal CA3 than in distal CA3, or in distal CA1 than in proximal CA1 at the time of killing, maximal electroconvulsive seizures (MECS) were induced in an additional group $(n=$ 4; MECS group). MECS were administered via earclip electrodes using a constant current generator (UGO Basile ECT unit 7801, UGO Basile: 85 $\mathrm{mA}, 100 \mathrm{~Hz}, 500 \mu$ s pulses, $1 \mathrm{~s}$ duration) (Cole et al., 1989; Guzowski et al., 1999; Vazdarjanova et al., 2006).

Brain collection. Animals were deeply anesthetized with isoflurane and decapitated. Brains were immediately collected, frozen in isopentane cooled in dry ice, and subsequently stored at $-80^{\circ} \mathrm{C}$. Brains were then coronally sectioned on a cryostat ( $8 \mu \mathrm{m}$ sections; Leica CM 3050S, Leica Microsystems), collected on polylysine-coated slides, and stored at $-80^{\circ} \mathrm{C}$.

Detection of Arc signal by in situ hybridization histochemistry. The Arc DNA template was designed to amplify a fragment containing two intron sequences from bases 1934-2722 of the rat Arc gene (NCBI Reference Seq: NC_005106.2). DIG-labeled Arc RNA probes were synthesized with a mixture of digoxigenin-labeled UTP (DIG RNA Labeling Mix, Roche Diagnostics) and purified using Probe quant G-50 Micro columns (GE Healthcare). Fluorescent in situ hybridization histochemistry was performed as previously described in the study by Nakamura et al. (2010) with modifications. In brief, sections were fixed with $4 \%$ paraformaldehyde in sterile $0.1 \mathrm{~m}$ PBS. Sections were rinsed in PBS and acetylated with $0.25 \%$ acetic anhydride in $0.1 \mathrm{~m}$ triethanolamine-HCl. Following prehybridization incubation, hybridization solution $(50 \%$ formamide, $5 \times$ SSC, $2.5 \times$ Denhardt's solution, $250 \mu \mathrm{g} / \mathrm{ml}$ yeast tRNA, $500 \mu \mathrm{g} / \mathrm{ml}$ denatured salmon sperm DNA, and $0.05 \mathrm{ng} / \mu \mathrm{l}$ digoxigenin-labeled Arc RNA probes) was applied to each slide $(200 \mu \mathrm{l})$. The sections were coverslipped and incubated in a humidified environment at $65^{\circ} \mathrm{C}$ for $17 \mathrm{~h}$. Sections were then rinsed in $5 \times$ SSC and then $0.2 \times$ SSC at $65^{\circ} \mathrm{C}$ for $1 \mathrm{~h}$. Sections were incubated with $1 \%$ bovine serum albumin (BSA) in TBST buffer $(0.1 \mathrm{M}$ Tris- $\mathrm{HCl}$ pH 7.4, $0.15 \mathrm{M} \mathrm{NaCl}, 0.05 \%$ Tween 20$)$ at room temperature, and then incubated with anti-digoxigenin-POD antisera (1/2000 dilution, Roche Diagnostics) in BSA/TBST at room temperature for $3 \mathrm{~h}$. Sections were rinsed in TBST, signal amplified using the Tyramide Signal Amplification (TSA) Cy5 system (Cy5 plus system, PerkinElmer), counterstained with DAPI (1/100,000 dilution, Life Technologies), and coverslipped. As controls for the staining, the detection was also performed without $A r c$ antisense probe, or with $A r c$ sense probe which led to the absence of Arc staining.

Image acquisition. CA1 and CA3 images were acquired using a $20 \times$ objective (Nikon) on a BZ-9000E fluorescent microscope (Keyence). A $z$-stack containing 13 images ( 545 by $724 \mu \mathrm{m}$ each; $0.7 \mu \mathrm{m}$ thickness) was acquired per region of interest on at least three nonadjacent sections. The exposure time, contrast, and gain settings were kept constant between image-stacks. Eight regions of interest were chosen from the hippocampus, according to the rat brain atlas (Paxinos and Watson, 2007). For the investigation of the proximodistal pattern of activity in CA3 and CA1 along the transverse axis of the hippocampus, four areas were selected at the following anteroposterior (AP) levels defined from the bregma: distal CA3 and proximal CA1 at the septal level: -3.1 to $-3.3 \mathrm{~mm} \mathrm{AP}$; proximal CA3 and distal CA 1 at the temporal level: -5.1 to $-5.3 \mathrm{~mm} \mathrm{AP}$ (Fig. $2 A, B)$. For the investigation of the proximodistal segregation of nonspatial information in CA3 and CA1 along the mediolateral axis of the hippocampus, four additional areas were selected at the same septal and the temporal levels: distal CA1 and proximal CA3 at the septal level: -3.1 to $-3.3 \mathrm{~mm}$ AP; distal CA3 and proximal CA1 at the temporal level: -5.1 to $-5.3 \mathrm{~mm}$ AP (see Fig. $4 A, C$, dashed frames).

Counting of Arc-positive cells. The number of Arc pre-mRNA-positive nuclei in the hippocampus was estimated as previously described in the study by Vazdarjanova and Guzowski (2004) with modifications. To account for stereological considerations, counting was performed on nonadjacent sections, and focused on the median $25 \%$ of each imagestack that was extracted from the $z$-stack and collapsed (West, 1999; Vazdarjanova and Guzowski, 2004). Briefly, non-neuron-like nuclei ( $~ 5$ $\mu \mathrm{m}$ in diameter) with intensely bright and uniform DAPI staining were excluded, whereas neuronal nuclei identified as large and diffusely DAPI stained were included in our analysis. Arc pre-mRNA-positive nuclei were defined as cells carrying one or two Cy5 tags within their nucleus, and the number of Arc pre-mRNA-positive nuclei was counted on three frames per area of interest on nonadjacent coronal sections (see Table 1 for detailed counts). Counting of Arc-positive nuclei and Arc-negative nuclei was performed manually by experimenters blind to experimental conditions with ImageJ (Image J1.46, National Institutes of Mental Health), and the percentage of Arc-positive cells per frame was calculated. Subsequently, "task-induced" proportions of Arc-positive cells were calculated for the DNMS and the random reward groups by subtracting the baseline Arc expression found in controls from counts obtained in the same area in animals performing the tasks.

Statistical analysis. For the behavioral task, one-way repeatedmeasures ANOVA was performed on the percentage correct choice for the last three training sessions, and two-tailed one-sample $t$ test for the comparisons to chance level ( $50 \%$ correct) for each of the three sessions. A one-sample $t$ test was performed for comparisons to zero to study the baseline Arc expression for each area of interest. Two-way repeatedmeasures ANOVA and two-tailed paired $t$ test were performed to compare task-induced proportions of Arc-positive cells in the proximal and distal parts of CA3 and CA1 along the transverse and the mediolateral axes of the hippocampus. All statistical analyses were performed using the software R 2.12.1 (R Foundation for Statistical Computing).

\section{Results}

\section{Memory performance}

Animals learned to discriminate between the 10 odors that belonged to the study list, and the 10 odors that did not over $26.4 \pm$ 2.1 training sessions (see Materials and Methods for a detailed description of the task). Accuracy did not significantly differ between animals over the last 3 days of testing $\left(F_{(2,8)}=2.30 ; p>\right.$ $0.05)$, but significantly differed from chance level (50\% correct choice; $2 \mathrm{~d}$ before death: $t_{(4)}=7.67, p=0.002 ; 1 \mathrm{~d}$ before death: $t_{(4)}=22.9, p<0.0001$; on day of killing: $t_{(4)}=9.95, p=0.0006$; Fig. $1 D)$. Animals reached on average a performance of $79.0 \pm$ $2.9 \%$ correct on day of killing (Fig. 1D).

\section{Location of the counting frames}

To compare activity patterns in corresponding proximal and distal portions of CA3 and CA1 at similar dorsoventral levels, we first studied the proximodistal pattern of activity of CA 3 and CA1 along the transverse axis of the hippocampus. This required distal 


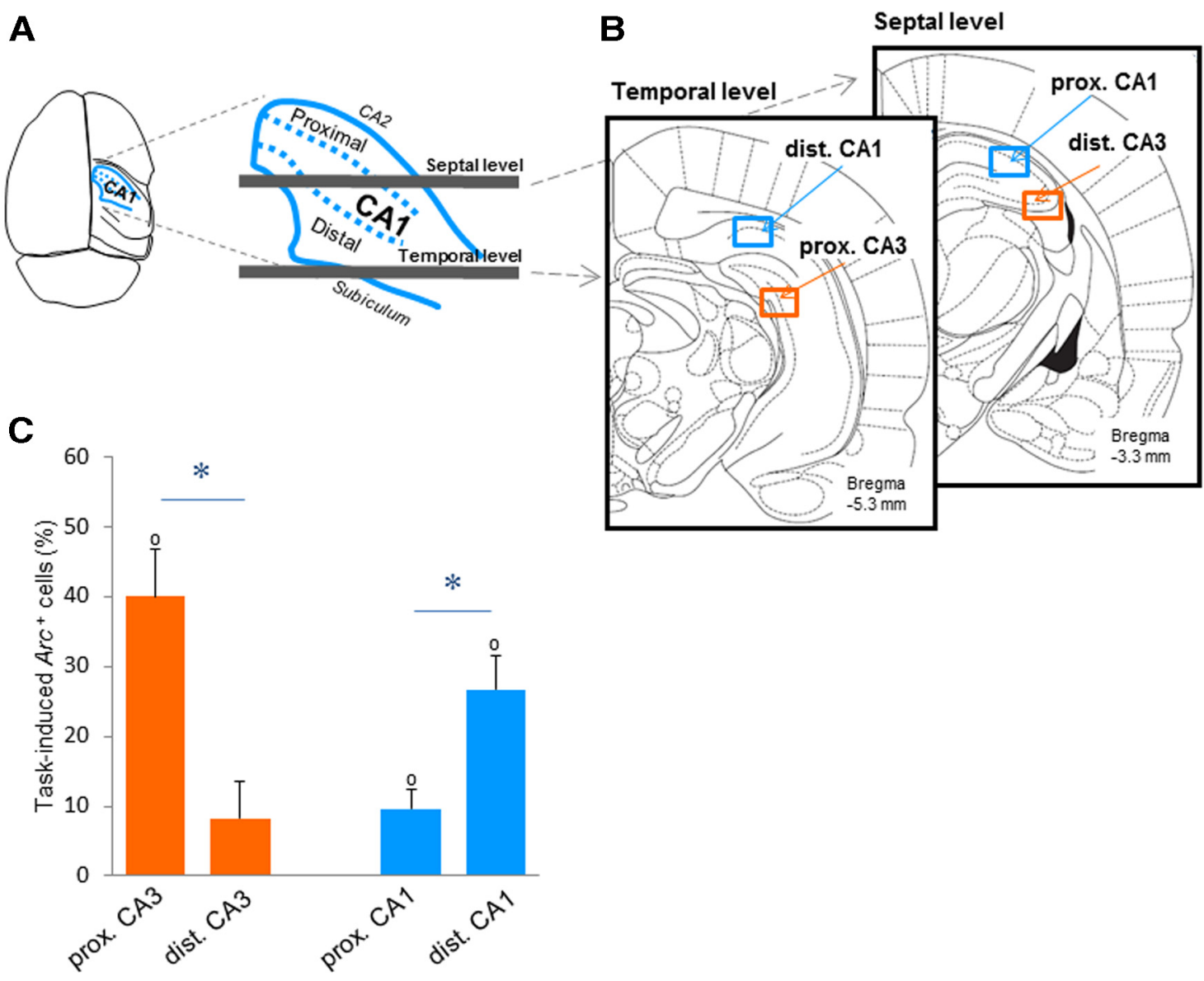

Figure 2. Proximodistal nonspatial representations along the transverse axis of CA1 and CA3.A, Location of the counting frames along the transverse axis of the hippocampus: dorsal view of the CA1 hippocampal subfield [inspired by Henriksen et al. (2010); note that CA3, which lies under CA1, is not represented]. Estimated borders between proximal and distal CA1 along the transverse axis of the hippocampus are indicated by blue dotted lines (note that the complex three-dimensional conformation of the hippocampus makes any standard planes of sectioning inappropriate for a correct assessment of its transverse organization). $\boldsymbol{B}$, To compare proximal and distal parts of (A1 (blue frames) or CA3 (red frames) at a corresponding dorsoventral level, and along the transverse axis of the hippocampus, counting frames were shifted from proximal CA1 (lateral) at the septal level to distal CA1 (medial) at the temporal level, and from distal CA3 (lateral) at the septal level to proximal CA3 (medial) at the temporal level (Andersen et al., 1971). C, The task-induced proportion of Arc-positive cells in the proximal and distal parts of CA3 and CA1 (left to right) in the DNMS group. The task-induced proportion of Arc-positive cells (means \pm SEM) is significantly higher in proximal CA3 and distal CA1 than in distal CA3 and proximal CA1 (respectively), suggesting that nonspatial information is not uniformly represented along the proximodistal axis of $C A 3$ and $C A 1 .{ }^{*} p<0.05$. Comparisons to $0:{ }^{\circ} p<0.05$.

CA3 and proximal CA1 counting frames to be collected on coronal sections at the septal level of the hippocampus, and proximal CA3 and distal CA1 counting frames to be collected at the temporal level (Andersen et al., 1971) (Fig. 2A,B). In addition, to study whether the proximodistal segregation of nonspatial information in CA3 and CA1 was also observable along the mediolateral axis of the hippocampus (Hunsaker et al., 2008; Ito and Schuman, 2012; that is also used in other studies), four additional frames were sampled on the same coronal sections: distal CA1 and proximal CA3 at the septal level of the hippocampus, and proximal CA1 and distal CA3 at the temporal level (see Fig. $4 A, C$, dashed frames). These frames allowed us to investigate whether the proximal and distal parts of CA3 and CA1 were differentially recruited during nonspatial recognition memory along the mediolateral axis of the hippocampus at the septal and temporal levels.

Baseline Arc expression along the transverse and mediolateral axes of the hippocampus

The baseline expression of $A r c$, in control animals that were exposed to the experimental room but did not perform the task, was low in the distal and proximal parts of CA3 and CA1 (on average
$7.59 \pm 1.73 \%$ of $A r c$-positive cells). The recruitment of these areas in control animals appeared to be minimal, since Arc expression did not significantly differ from zero for any area, but proximal CA1 at the septal level $\left(t_{(3)}=3.35, p=0.04\right.$, all other $p$ values $>0.05$ ). Because of this slight difference in baseline Arc expression, the proportions of Arc-positive cells detected in the DNMS and the random reward groups were normalized by subtracting the proportion of Arc-positive cells obtained in control animals for the same areas to enable a direct comparison between regions (see Table 1 for cell counts). These task-induced proportions of Arc-positive cells were subsequently used for statistical analysis.

\section{Proximodistal nonspatial representations in CA3 and CA1 along the transverse axis of the hippocampus}

Two-way ANOVA with "hippocampal subfield" and "proximodistal location" as factors conducted on the task-induced proportion of Arc-positive cells measured along the transverse axis of the hippocampus revealed a significant proximodistal $\times$ subfield interaction $\left(F_{(1,4)}=23.2, p=0.009\right)$, while no further significant effects were observed (proximodistal: $F_{(1,4)}=1.37$, subfield: $F_{(1,4)}=2.88$, both $p$ values $>0.05$; Fig. $2 C$ ). Moreover, further sta- 
tistical analysis showed that task-induced proportions of Arcpositive cells were significantly higher in proximal CA3 than in distal CA3 $\left(t_{(4)}=2.97, p=0.04\right.$; Figs. $\left.2 C, 3 A, B\right)$. This indicated a preferential recruitment of proximal CA3 over distal CA3 during nonspatial recognition memory and pointed toward a functional segregation of CA3 in nonspatial memory. Furthermore, in line with the preferential projections existing between proximal CA3 and distal CA1 (Ishizuka et al., 1990; Li et al., 1994; and between distal CA3 and proximal CA1), distal CA1 was significantly more recruited than proximal CA1 during the task $\left(t_{(4)}=4.22, p=0.01\right.$; Figs. $\left.2 C, 3 C, D\right)$. This result confirmed previous findings of a functional segregation of CA1 in studies based on the detection of item novelty (Burke et al., 2011; Ito and Schumann, 2012), and further suggested that this functional segregation holds for tasks with a higher memory load. Finally, task-induced proportions of $A r c$-positive cells were comparable in the parts of CA3 and CA1 that project to each other: proximal CA3 and distal CA1, and distal CA3 and proximal CA1 $\left(t_{(4)}=1.88, t_{(4)}=\right.$ 0.20 , respectively, both $p$ values $>0.05$; Fig. $2 C$ ), suggesting that proximal CA3 and distal CA1 could belong to the same functional network, and distal CA3 and proximal CA1 to another one. Of note, the task-induced proportion of Arc-positive cells differed from zero for all areas, but distal CA3 (distal CA3: $t_{(4)}=1.53, p>0.05$, all other areas $p<0.03$ ). However, a careful inspection of the latter data suggests that the comparison fails to reach significance because of a SEM slightly higher in distal CA3 than in other areas (see for example proximal CA1; Fig. 2C). In summary, these results show that proximal CA3 is significantly more activated than distal CA3 during nonspatial recognition memory, suggesting that nonspatial information could be segregated along the proximodistal axis of CA3. Likewise, in accordance with the fact that proximal CA3 preferentially projects to distal CA1, distal CA1 was more recruited than proximal CA1 during this task, and proximal CA3 and distal CA1 were activated to a similar level. Together, these results bring evidence for a nonuniform distribution of nonspatial information along the proximodistal axis of CA3 and CA1, and suggest that the proximal CA3-distal CA1 network could be preferentially recruited over the distal CA3-proximal CA1 network during nonspatial recognition memory.

\section{Proximodistal nonspatial}

representations along the mediolateral axis of CA 3 and CA1 at septal and temporal levels of the hippocampus To ensure that our findings were not simply resulting from the level at which counting frames were collected (e.g., along the transverse axis), and for the sake of comparisons with studies which used coronal plans of sectioning (Hunsaker et al., 2008; Ito and Schuman, 2012), we investigated whether the proximodistal segregation of nonspatial information in CA3 and CA1 that we observed along the transverse axis was also conserved at septal and temporal levels along the mediolateral axis of the hippocampus. To do so, we sampled four additional counting frames on the coronal sections previously sampled: one distal CA1 and one proximal CA3 frames at the septal level, and one proximal CA1 and one distal
Table 1. Number of Arc-positive neuronal cells and total cell counts in the control, DNMS, random reward, and MECS groups along the transverse and mediolateral axes of the hippocampus (septal and temporal levels)

\begin{tabular}{lllll}
\hline & CA3 & & CA1 & \\
\cline { 2 - 3 } \cline { 5 - 6 } & Number of & & Number of & Number of \\
Group & Arc + cells & Number of cells & Arc + cells & neuronal cells \\
& Mean \pm SE & Mean \pm SE & Mean \pm SE & Mean \pm SE \\
\hline
\end{tabular}

\begin{tabular}{lclcl}
\hline $\begin{array}{l}\text { Proximal (temporal) } \\
\text { Control }\end{array}$ & $8.35 \pm 5.32$ & $211.56 \pm 7.04$ & $14.51 \pm 5.57$ & $360.50 \pm 7.88$ \\
DNMS & $116.00 \pm 22.30$ & $256.46 \pm 14.93$ & $57.49 \pm 5.56$ & $359.74 \pm 12.95$ \\
Random & $24.73 \pm 28.63$ & $254.94 \pm 5.93$ & $28.98 \pm 8.07$ & $366.26 \pm 11.61$ \\
$\quad$ MECS & $180.20 \pm 7.42$ & $227.80 \pm 3.48$ & $314.20 \pm 26.57$ & $387.00 \pm 10.66$ \\
Distal (septal) & & & & \\
$\quad$ Control & $40.03 \pm 14.38$ & $263.75 \pm 11.00$ & $38.48 \pm 19.34$ & $374.88 \pm 14.76$ \\
DNMS & $68.47 \pm 19.61$ & $284.93 \pm 22.81$ & $119.40 \pm 6.46$ & $386.72 \pm 30.58$ \\
Random & $53.16 \pm 10.23$ & $275.58 \pm 18.93$ & $77.12 \pm 7.84$ & $401.82 \pm 20.86$ \\
MECS & $239.80 \pm 6.25$ & $308.00 \pm 6.37$ & $293.20 \pm 10.24$ & $364.40 \pm 4.41$ \\
Proximal (septal) & & & & \\
$\quad$ Control & $17.31 \pm 15.16$ & $202.13 \pm 11.03$ & $53.19 \pm 17.07$ & $410.38 \pm 11.99$ \\
DNMS & $62.26 \pm 14.45$ & $217.23 \pm 18.15$ & $90.23 \pm 9.49$ & $409.19 \pm 31.27$ \\
Random & $34.40 \pm 10.73$ & $236.04 \pm 19.61$ & $66.94 \pm 16.53$ & $368.04 \pm 16.88$ \\
MECS & $153.00 \pm 2.62$ & $196.80 \pm 3.50$ & $323.20 \pm 6.12$ & $400.00 \pm 6.98$ \\
Distal (temporal) & & & & \\
Control & $11.92 \pm 5.60$ & $313.50 \pm 8.27$ & $21.07 \pm 7.31$ & $369.25 \pm 17.00$ \\
DNMS & $93.37 \pm 12.14$ & $302.64 \pm 7.53$ & $138.72 \pm 19.99$ & $432.74 \pm 11.08$ \\
Random & $26.07 \pm 27.08$ & $253.44 \pm 25.25$ & $64.98 \pm 26.75$ & $409.50 \pm 24.33$ \\
MECS & $229.75 \pm 14.65$ & $291.50 \pm 10.76$ & $316.20 \pm 17.27$ & $392.40 \pm 5.59$ \\
\hline
\end{tabular}

Data are reported as means \pm SEM.
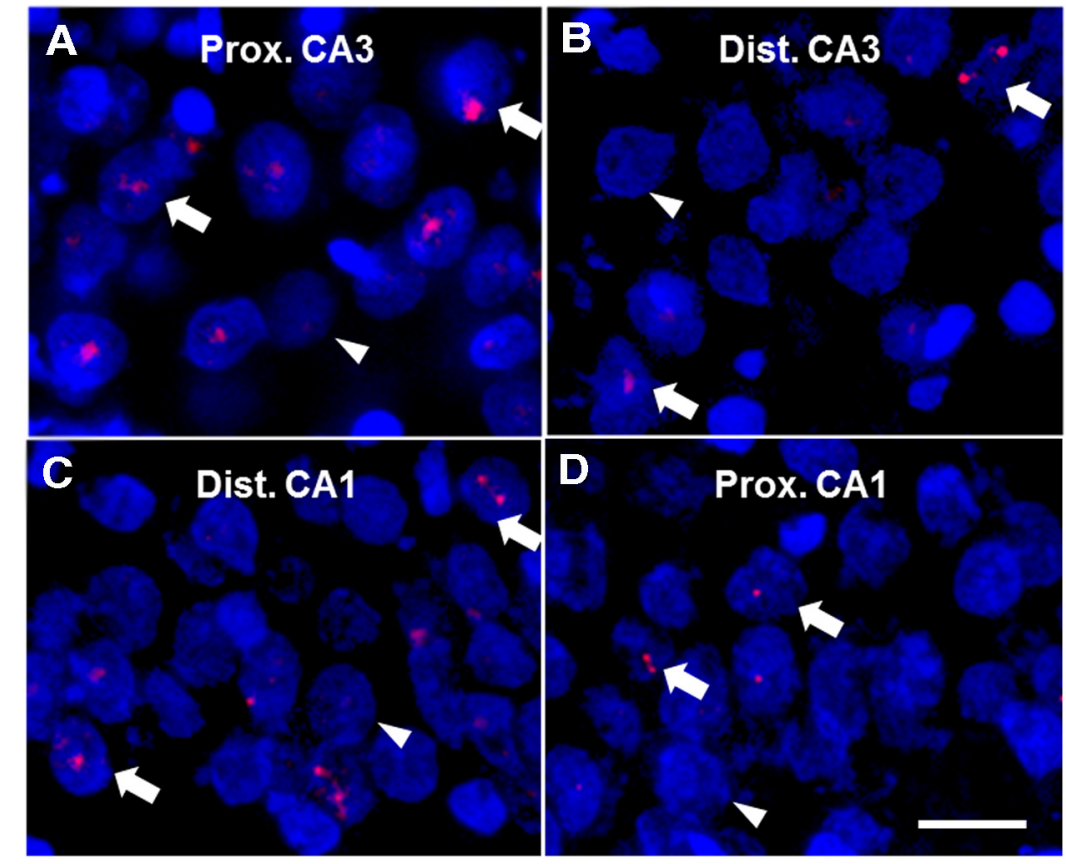

Figure 3. Arc expression in proximal and distal parts of $C A 3$ and $C A 1$ along the transverse axis of the hippocampus. Representative images of $\operatorname{Arc}$ expression in proximal CA3 $(\boldsymbol{A})$, distal CA3 $(\boldsymbol{B})$, distal CA1 $(\boldsymbol{C})$, and proximal CA1 (D) in the DNMS group. DAPI-stained nuclei are shown in blue and Arc intranuclear signal in red. Arrows show examples of Arc-positive cells, and arrowheads show examples of Arc-negative cells. Proximal CA3 and distal CA1 displayed significantly more Arc-positive cells than distal CA3 and proximal CA1, respectively. Scale bar, $20 \mu \mathrm{m}$.

CA3 frame at the temporal level of the hippocampus (Fig. $4 A, C$, dashed frames). Mirroring the results observed along the transverse axis, statistical analysis revealed that the four additional areas were also recruited during the task, since the task-induced proportion of $A r c$-positive cells in all areas significantly differed 


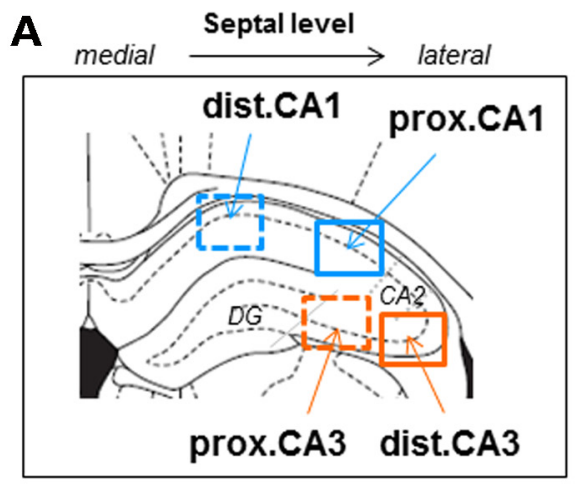

B

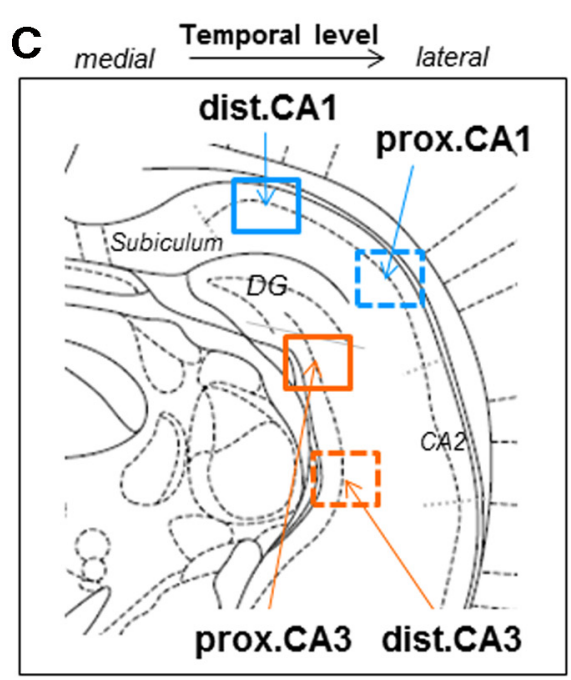

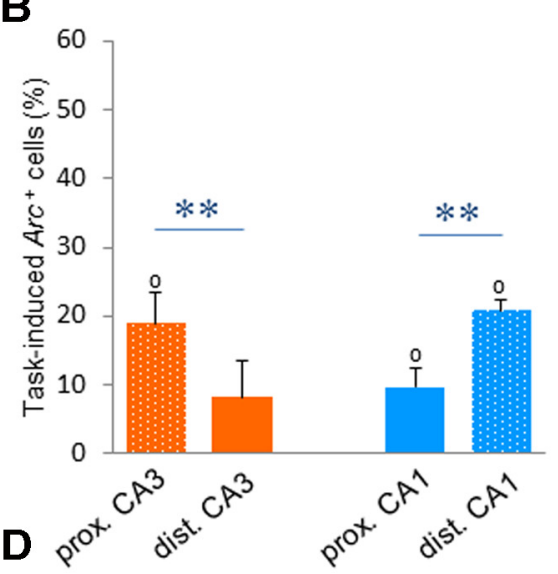

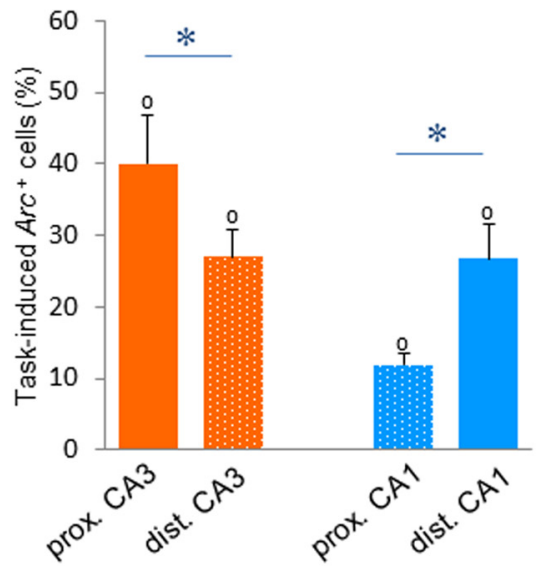

Figure 4. Proximodistal nonspatial representations along the mediolateral axis of CA3 and CA1 at the septal and temporal levels of the hippocampus. To investigate the proximodistal segregation of nonspatial information in CA3 and CA1 at the septal and temporal levels, four additional frames (dashed frames) were sampled: distal CA1 and proximal CA3 at the septal level $(\boldsymbol{A})$, and proximal $C A 1$ and distal $C A 3$ at the temporal level $(\boldsymbol{C})$, in addition to the four frames (plain frames) already described in Figure $2 B . \boldsymbol{B}, \boldsymbol{D}$, Results at the septal and temporal levels of the hippocampus mirror those along the transverse axis: the task-induced proportion of Arc-positive cells (means \pm SEM) is significantly higher in proximal CA3 and distal CA1 when compared with that of distal CA3 and proximal CA1, respectively. This suggests that nonspatial information is not uniformly distributed along the proximodistal axis of $C A 3$ and $C A 1$ throughout the hippocampus. ${ }^{*} p<0.05,{ }^{* *} p<0.005$. Comparison to $0:{ }^{\circ} p<0.05$.

from zero ( $p<0.02$; dotted bars in Fig. $4 B, D$, plain bars represent data shown in Fig. 2C). Moreover, comparisons of taskinduced proportions of Arc-positive cells between proximal CA3, distal CA1, proximal CA1, and distal CA3 at the septal or temporal level revealed a significant hippocampal subfield $\times$ proximodistal interaction (septal: $F_{(1,4)}=309.0, p<0.0001$; temporal: $\left.F_{(1,4)}=21.2, p=0.01\right)$, a main subfield effect at the temporal level $\left(F_{(1,4)}=8.11, p=0.04\right)$, and no further significant effects $(p>0.05$; Fig. $4 B, D$ ). In further agreement with the observations along the transverse axis, proximal CA3 was significantly more activated during the task than distal CA3 at the septal and temporal levels (septal level: $t_{(4)}=8.41, p=0.001$; temporal level: $\left.t_{(4)}=2.90, p=0.04\right)$, and distal CA1 was more activated than proximal CA1 (septal level: $t_{(4)}=$ $6.39, p=0.003$; temporal level: $t_{(4)}=4.08, p=0.02$; Fig. $4 B, D$, respectively). Furthermore, proximal CA3 and distal CA1 (which project to each other) displayed comparable levels of task-induced positive cells (septal: $t_{(4)}=0.31$; temporal: $t_{(4)}=1.88$, both $p$ values $>0.05$ ), which was also the case for distal CA3 and proximal CA1 at the septal level, but not at the temporal level (septal: $t_{(4)}=0.20, p>$ 0.05 ; temporal: $\left.t_{(4)}=4.00, p=0.02\right)$. Together, these data show that the functional segregation of $\mathrm{CA} 3$ and $\mathrm{CA} 1$ observed along the trans-

verse axis of the hippocampus during nonspatial recognition memory is conserved along its mediolateral axis at the septal and temporal levels, and that the functional dissociation between the proximal CA3-distal CA1 network and the distal CA3-proximal CA1 network seems to persist at various levels of the hippocampus.

\section{Proximodistal Arc expression in CA1 and $\mathrm{CA} 3$ in the random reward and the MECS groups}

To evaluate whether testing conditions, such as the presentation of the stimulus cups, motor demands, or handling, could lead to the pattern of activation that we obtained in CA3 and CA1 in the DNMS group, we detected Arc expression in the random reward group (see Table 1 for cell counts). Among the eight areas sampled along the transverse and mediolateral axes, the task-induced proportion of Arcpositive cells differ from zero only in one: distal CA1 at the septal level $\left(t_{(4)}=4.96\right.$, $p=0.008$; all other $p$ values $>0.05$; Fig. $5 A-C$ ), suggesting a minimal recruitment of CA1 and CA3 when no memory demand was applied to the behavioral task. In addition, no significant main effects or proximodistal by subfield interactions were observed along the transverse (Fig. $5 A)$ and mediolateral axes at the septal (Fig. $5 B ; p>0.05$ ) or temporal levels of the hippocampus (Fig. $5 C ; p>0.05$ ), and only a main proximodistal effect could be found at the septal level $\left(F_{(1,4)}=14.35\right.$, $p=0.02$; Fig. $5 B)$. Moreover, the taskinduced proportion of Arc-positive cells were comparable between proximal CA3 and distal $\mathrm{CA} 3$, and between proximal CA1 and distal CA1 along the transverse axis $\left(\mathrm{CA} 3: t_{(4)}=0.01\right.$; CA1: $t_{(4)}=0.63$, both $p$ values $>0.05$; Fig. $5 A$ ) and the mediolateral axis at the septal level (CA3: $t_{(4)}=0.30$; CA1: $t_{(4)}=1.51$; both $p$ values $>0.05$, Fig. $5 B$ ) and the temporal level (CA3: $t_{(4)}=0.91$; CA1: $t_{(4)}$ $=1.64, p>0.05$, Fig. $5 C$ ), indicating that the differences observed between proximal CA3 and distal CA3, and between distal $\mathrm{CA} 1$ and proximal CA1 during the nonspatial memory task were unlikely due to testing conditions alone.

Finally, we tested whether the pattern of Arc expression that we obtained in the DNMS group could be due to a higher likelihood for proximal CA 3 and distal CA1 to express Arc at the time of death than for distal CA3 and proximal CA1. We induced seizure-like activity in MECS animals and killed them under the same conditions as the DNMS animals. Arc expression induced by MECS was high in all areas (79.53 $\pm 0.48 \%$ of Arc-positive cells in average; see Table 1 for cell counts), and significantly different from zero $(p<0.0002$; Fig. $6 A-C)$. In addition, the proportions of cells activated were virtually indistinguishable between areas: no significant proximodistal by subfields interactions could be detected along the transverse or the mediolateral axes at the septal and temporal levels $(p>0.05)$ and only a significant main subfield effect was found along transverse axis 

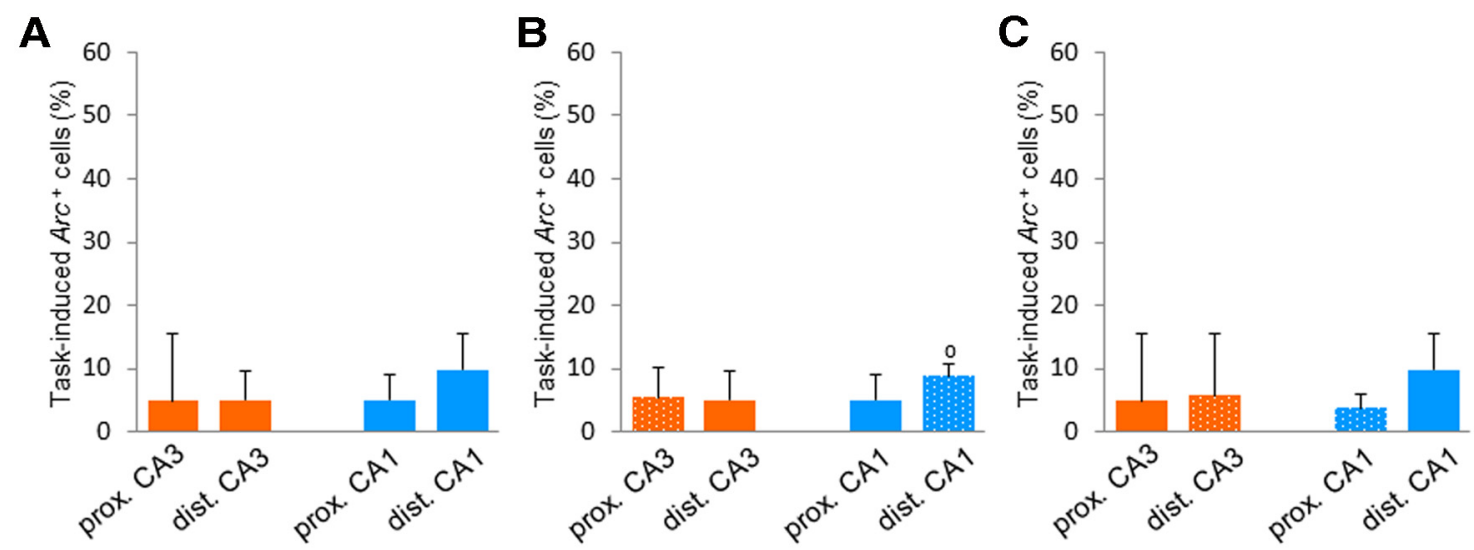

Figure 5. Task-induced Arc expression in proximal and distal parts of $C A 3$ and $C A 1$ in the random reward group. In the random reward group, the task-induced proportion of Arc-positive cells (means \pm SEM) does not differ between the proximal and distal parts of CA3 and CA1 along the transverse axis $(\boldsymbol{A})$ and mediotemporal axis at the septal $(\boldsymbol{B})$ and temporal $(\boldsymbol{C})$ levels, suggesting that testing conditions alone did not lead to the pattern of activation found in the DNMS group. Comparison to $0:{ }^{\circ} p<0.05$.
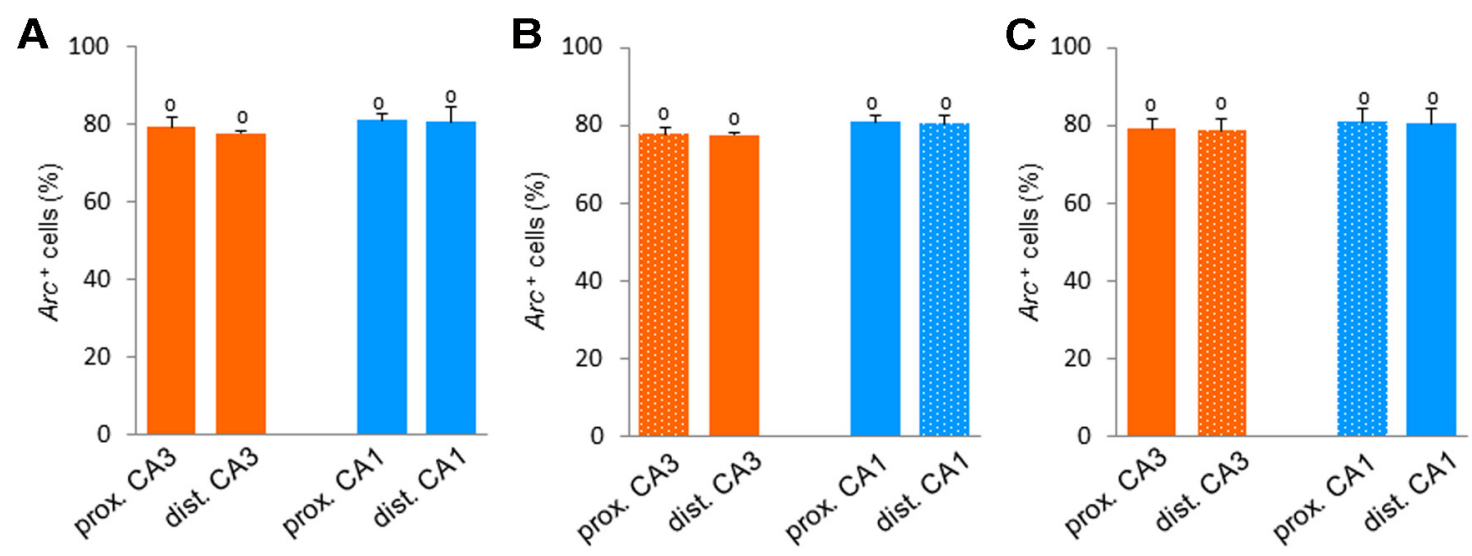

Figure 6. Task-induced Arcexpression in proximal and distal parts of CA3 and CA1 in the MECS group. The proportion of Arc-positive cells induced by MECS (means \pm SEM) does not differ between proximal and distal parts of CA3 and $C A 1$ along the transverse axis $(\boldsymbol{A})$ and mediotemporal axis at the septal $(\boldsymbol{B})$ and temporal $(\boldsymbol{C})$ levels, showing that proximal and distal parts of $C A 3$ and $C A 1$ were capable of expressing Arc to a similar level at the time of death. Comparison to 0: ${ }^{\circ} p<0.0005$.

$\left(F_{(1,3)}=12.74, p=0.04\right)$. Hence, as expected in this case, no significant differences were found between the proximal and distal parts of CA3, or between the proximal and distal parts of CA1 at any levels $(p>0.05$, Fig. $6 A-C)$. Thus, our results show that all parts of CA1 and CA3 have a comparable "capacity" to express $A r c$ at the time at which the DNMS group was killed, suggesting that the differential expression of Arc in the proximal and distal parts of CA3 and CA1 during the memory task is likely due to memory retrieval.

\section{Discussion}

We bring the first evidence for a functional segregation of the CA3 hippocampal subfield in terms of its recruitment in recognition memory for nonspatial information, and found that the proximal part of CA3 is preferentially recruited during nonspatial memory when compared with its distal part. In addition, our data support and extend previous findings indicating that the distal part of CA1 is more involved in the processing of nonspatial information than its proximal part, even in tasks that involve a high memory load and are devoid of salient spatial content. These results together with the fact that proximal CA3 projects mainly to distal CA1, suggest that a selective proximal CA3-distal CA1 hippocampal subnetwork could preferentially support nonspatial recognition memory.
Our results show that CA3 is recruited during nonspatial recognition memory, a topic that has received little attention to date. These data give further support to previous studies that report that CA3 plays a critical role in the memory for pairs of odors (Farovik et al., 2010) and eye-blinking conditioning (Kishimoto et al., 2006; Thompson et al., 1996). However, in contrast with these studies, we investigated the existence of a functional segregation within CA3. We found a nonuniform distribution of nonspatial information along the proximodistal axis of $\mathrm{CA} 3$, and report that proximal CA3 is more activated than distal CA3 during nonspatial recognition memory. This phenomenon is observable not only along the "functional" axis of the hippocampus (the transverse axis), but also along its mediolateral axis at the septal and temporal levels, suggesting that nonspatial information is processed preferentially by proximal CA3 throughout the hippocampus.

Arc plays a crucial role in synapse-specific and cell-wide plasticity processes (Link et al., 1995; Lyford et al., 1995) (for review, see Bramham et al., 2008; Korb and Finkbeiner, 2011; Shepherd and Bear, 2011) and its expression was shown to better reflect behavioral task demands than other IEGs, such as $c$-fos and zif268 (Guzowski et al., 1999, 2001). Moreover, Arc expression has been repeatedly reported to reflect the task's behavioral demands, and 
not simply reflect stress levels or motor activity (Guzowski et al., 1999, 2001, 2006). In the present study, control animals and animals performing the DNMS task share the same spatial experience (exposure to the testing room), and only nonspatial demands differed between groups. Hence, the task-induced Arc expression in this study is thought to reflect the processing of nonspatial information. In further support to this idea, taskinduced Arc expression in the random reward group (group with no memory retrieval) did not significantly differ between the proximal and distal parts of CA3 or CA1, suggesting that the pattern of Arc expression found in the DNMS group is likely caused by memory retrieval of nonspatial information. Moreover, using MECS, we have shown that both the proximal and distal parts of CA3 and CA1 were capable of expressing $A r c$ at the time of death, further speaking in favor of the specificity of our findings.

Proximal CA3 receives little direct input from the EC layer II when compared with distal CA3 (Li et al., 1994; Ishizuka et al., 1995), because the lacunosum moleculare layer, in which EC and CA3 cells synapse, is nearly absent at this level of CA3. Hence, one way in which proximal CA3 could contribute to nonspatial memory is by further processing information from the EC layer II that is relayed by the DG (Steward and Scoville, 1976; Witter and Amaral, 1991). Indeed, the granule cells of the DG receive inputs from both the lateral EC and the medial EC, albeit at different levels of the dendritic tree with the medial EC inputs closer to the cell layer and the inputs from lateral EC further away (Steward and Scoville, 1976; Witter et al., 1989). Striking electrophysiological and neuroanatomical differences exist between the exposed and the enclosed blades of the DG, which also differ in their susceptibility to hypoxia and corticosteroid insults (Hara et al., 1990; Jaarsma et al., 1992; Scharfman et al., 2002) (for review, see Amaral et al., 2007). The functional relevance of those differences has not been thoroughly investigated, however, an IEG study based on Arc RNA expression revealed that the exposed blade of the DG was not recruited during exposure to new spatial contexts, whereas the enclosed blade was (Chawla et al., 2005). Furthermore, granule cells of the exposed blade of the DG project principally to the proximal part of $\mathrm{CA} 3$, while the neurons of the enclosed blade of the DG preferentially project to the distal part of CA3 (Claiborne et al., 1986) (for review, see Witter, 2007). Given this preferential pattern of projections, and the fact that proximal CA3 is more activated than distal CA3 during our nonspatial memory task, it is tempting to speculate that the exposed blade of the DG could preferentially relay nonspatial information to proximal CA3, while projections from the enclosed blade to distal CA 3 could relay spatial information. This hypothesis, however, remains to be thoroughly investigated.

In addition, in the present study we report a stronger activation of distal CA1 (the part of CA1 that principally receives proximal CA3 inputs) during nonspatial recognition memory when compared with proximal CA1 (which mainly receives distal CA3 inputs) (Amaral and Witter, 1989; Ishizuka et al., 1990; Li et al., 1994). This finding of a heterogeneous distribution of nonspatial representations along the proximodistal axis of CA1 is consistent with two recent studies that have investigated the same topic albeit in tasks based on spatial navigation or spontaneous exploration (Burke et al., 2011; Ito and Schuman, 2012; e.g., with low memory load as opposed to the high memory load in this study). In further contrast to the present study, Ito and Schuman (2012) restricted their investigation to the analysis of the proximodistal pattern of Fos expression in the hippocampus along the mediolateral axis of the hippocampus, instead of investigating differ- ences along the transverse axis, which is the functional axis of the hippocampus. Also, Burke et al. (2011) focused on the cell firing in distal CA1 under "object-present" and "object-absent" conditions, but did not study the firing pattern of proximal CA1. Both of these electrophysiological and IEG studies reported a critical role of distal CA1 in the processing of nonspatial information, as cell firing in distal CA1 was affected by the presence/absence of objects in a spatial navigation task (Burke et al., 2011), and distal CA1 was more activated than proximal CA1 in a spontaneous object recognition memory task (Ito and Schuman, 2012). In the present study, we also found that distal CA1 is more recruited than proximal CA1. In addition, we know that the lateral EC preferentially projects to distal CA1 and that distal CA1 preferentially receives projections from proximal CA3. Hence, it is tempting to speculate that the activation observed in distal CA1 during the recognition phase of our task could reflect nonspatial pattern separation between the representations created during the study phase and the representations generated during the recognition phase of the task. This hypothesis is at least partially supported by reports suggesting a critical role of CA1 in conjunction with CA3 during nonspatial pattern separation, and a strong involvement of CA1 in the interpretation/recoding of CA 3 inputs in the context of less spatially restricted information (for review, see Kesner et al., 2004, Leutgeb and Leutgeb, 2007; Rolls, 2010).

In summary, we have shown that proximal CA3 and distal CA1 are significantly more recruited than distal CA3 and proximal CA1 during recognition memory that is devoid of salient spatial information. These results suggest that not only CA1 is functionally segregated along its proximodistal axis, but also CA3, which has not been reported to date. Given that proximal CA3 and distal CA1 share direct projections, we speculate that proximal CA3 and distal CA1 could be part of a selective functional subnetwork in the hippocampus that could preferentially process recognition memory when the salient part of a representation is restricted to its nonspatial content. In our DNMS task, spatial information is not crucial, thus the integration of the spatial context within the memory representation is not critical, and pattern completion not "required." This could lead to a low recruitment of distal CA3 during nonspatial recognition memory, which contains the highest density of recurrent projections and is thought to support pattern completion (for review, see Gilbert and Brushfield, 2009). Testing this intricate network, and elucidating whether the functional segregation of CA1 directly results from the pattern of activity of CA3 is beyond the scope of this study and will require further investigation.

\section{References}

Amaral DG, Witter MP (1989) The three-dimensional organization of the hippocampal formation: a review of anatomical data. Neuroscience 31: 571-591. CrossRef Medline

Amaral DG, Scharfman HE, Lavenex P (2007) The dentate gyrus: fundamental neuroanatomical organization (dentate gyrus for dummies). Prog Brain Res 163:3-22. CrossRef Medline

Andersen P, Bliss TV, Skrede KK (1971) Lamellar organization of hippocampal pathways. Exp Brain Res 13:222-238. Medline

Bramham CR, Worley PF, Moore MJ, Guzowski JF (2008) The immediate early gene arc/arg3.1: regulation, mechanism, and function. J Neurosci 28:11760-11767. CrossRef Medline

Burke SN, Maurer AP, Nematollahi S, Uprety AR, Wallace JL, Barnes CA (2011) The influence of objects on place field expression and size in distal hippocampal CA1. Hippocampus 21:783-801. CrossRef Medline

Chawla MK, Guzowski JF, Ramirez-Amaya V, Lipa P, Hoffman KL, Marriott LK, Worley PF, McNaughton BL, Barnes CA (2005) Sparse, environmentally selective expression of Arc RNA in the upper blade of the rodent fascia dentata by brief spatial experience. Hippocampus 15:579-586. Medline 
Claiborne BJ, Amaral DG, Cowan WM (1986) (1986) A light and electron microscopic analysis of the mossy fibers of the rat dentate gyrus. J Comp Neurol 246:435-458. CrossRef Medline

Cole AJ, Saffen DW, Baraban JM, Worley PF (1989) Rapid increase of an immediate earle gene messenger RNA in hippovcampal neurons by synaptic NMDA receptor activation. Nature 340:474-476. CrossRef Medline

Deshmukh SS, Knierim JJ (2011) Representation of nonspatial and spatial information in the lateral entorhinal cortex. Front Behav Neurosci 5:69. Medline

Farovik A, Dupont LM, Eichenbaum H (2010) Distinct roles for dorsal CA3 and CA1 in memory for sequential nonspatial events. Learn Mem 17:12-17. Medline

Fyhn M, Molden S, Witter MP, Moser EI, Moser MB (2004) Spatial representation in the entorhinal cortex. Science 305:1258-1264. CrossRef Medline

Gilbert PE, Brushfield AM (2009) The role of the CA3 hippocampal subregion in spatial memory: a process oriented behavioral assessment. Prog Neuropsychopharmacol Biol Psychiatry 33:774-781. CrossRef Medline

Guzowski JF, McNaughton BL, Barnes CA, Worley PF (1999) Environmentspecific expression of the immediate-early gene Arc in hippocampal neuronal ensembles. Nat Neurosci 2:1120-1124. CrossRef Medline

Guzowski JF, Setlow B, Wagner EK, McGaugh JL (2001) Experiencedependent gene expression in the rat hippocampus after spatial learning: a comparison of the immediate-early genes Arc, c-fos, and zif268. J Neurosci 21:5089-5098. Medline

Guzowski JF, Timlin JA, Roysam B, McNaughton BL, Worley PF, Barnes CA (2005) Mapping behaviorally relevant neural circuits with immediateearly gene expression. Curr Opin Neurobiol 15:599-606. CrossRef Medline

Guzowski JF, Miyashita T, Chawla MK, Sanderson J, Maes LI, Houston FP, Lipa P, McNaughton BL, Worley PF, Barnes CA (2006) Recent behavioral history modifies coupling between cell activity and Arc gene transcription in hippocampal CA1 neurons. Proc Natl Acad Sci U S A 103: 1077-1082. CrossRef Medline

Hara H, Onodera H, Kogure K, Akaike N (1990) The regional difference of neuronal susceptibility in the dentate gyrus to hypoxia. Neurosci Lett 115:189-194. CrossRef Medline

Hargreaves EL, Rao G, Lee I, Knierim JJ (2005) Major dissociation between medial and lateral entorhinal input to dorsal hippocampus. Science 308: 1792-1794. CrossRef Medline

Henriksen EJ, Colgin LL, Barnes CA, Witter MP, Moser MB, Moser EI (2010) Spatial representation along the proximodistal axis of CA1. Neuron 68:127-137. CrossRef Medline

Hunsaker MR, Rosenberg JS, Kesner RP (2008) The role of the dentate gyrus, CA3a,b, and CA3c for detecting spatial and environmental novelty. Hippocampus 18:1064-1073. CrossRef Medline

Ishizuka N, Weber J, Amaral DG (1990) Organization of intrahippocampal projections originating from CA3 pyramidal cells in the rat. J Comp Neurol 295:580-623. CrossRef Medline

Ishizuka N, Cowan WM, Amaral DG (1995) A quantitative analysis of the dendritic organization of pyramidal cells in the rat hippocampus. J Comp Neurol 362:17-45. CrossRef Medline

Ito HT, Schuman EM (2012) Functional division of hippocampal area CA1 via modulatory gating of entorhinal cortical inputs. Hippocampus 22: 372-387. CrossRef Medline

Jaarsma D, Postema F, Korf J (1992) Time course and distribution of neuronal degeneration in the dentate gyrus of rat after adrenalectomy: a silver impregnation study Hippocampus 2:143-150. CrossRef

Kesner RP (2007) Behavioral functions of the CA3 subregion of the hippocampus. Learn Mem 14:771-781. CrossRef Medline

Kesner RP, Lee I, Gilbert P (2004) behavioral assessment of hippocampal function based on a subregional analysis. Rev Neurosci 15:333-351. Medline

Kishimoto Y, Nakazawa K, Tonegawa S, Kirino Y, Kano M (2006) Hippocampal CA3 NMDA receptors are crucial for adaptive timing of trace eyeblink conditioned response. J Neurosci 26:1562-1570. CrossRef Medline

Korb E, Finkbeiner S (2011) Arc in synaptic plasticity: from gene to behavior. Trends Neurosci 34:591-598. CrossRef Medline

Leutgeb S, Leutgeb JK (2007) Pattern separation, pattern completion, and new neuronal codes within a continuous CA3 map. Learn Mem 14:745757. CrossRef Medline
Li XG, Somogyi P, Ylinen A, Buzsáki G (1994) The hippocampal CA3 network: an in vivo intracellular labeling study. J Comp Neurol 339:181-208. CrossRef Medline

Link W, Konietzko U, Kauselmann G, Krug M, Schwanke B, Frey U, Kuhl D (1995) Somatodendritic expression of an immediate early gene is regulated by synaptic activity. Proc Natl Acad Sci U S A 92:5734-5738. CrossRef Medline

Lyford GL, Yamagata K, Kaufmann WE, Barnes CA, Sanders LK, Copeland NG, Gilbert DJ, Jenkins NA, Lanahan AA, Worley PF (1995) Arc, a growth factor and activity-regulated gene, encodes a novel cytoskeletonassociated protein that is enriched in neuronal dendrites. Neuron 14:433445. CrossRef Medline

Naber PA, Lopes da Silva FH, Witter MP (2001) Reciprocal connections between the entorhinal cortex and hippocampal fields CA1 and the subiculum are in register with the projections from CA1 to the subiculum. Hippocampus 11:99-104. CrossRef Medline

Nakamura NH, Fukunaga M, Akama KT, Soga T, Ogawa S, Pavlides C (2010) Hippocampal cells encode places by forming small anatomical clusters. Neuroscience 166:994-1007. CrossRef Medline

Paxinos G, Watson C (2007) The rat brain in stereotaxic coordinates, Ed 6. San Diego: Academic.

Rolls ET (2007) An attractor network in the hippocampus: theory and neurophysiology. Learn Mem 14:714-731. CrossRef Medline

Rolls ET (2010) A computational theory of episodic memory formation in the hippocampus. Behav Brain Res 215:180-196. CrossRef Medline

Sauvage MM (2010) ROC in animals: uncovering the neural substrates of recollection and familiarity in episodic recognition memory. Conscious Cogn 19:816-828. CrossRef Medline

Sauvage MM, Fortin NJ, Owens CB, Yonelinas AP, Eichenbaum H (2008) Recognition memory: opposite effects of hippocampal damage on recollection and familiarity. Nat Neurosci 11:16-18. CrossRef Medline

Sauvage MM, Beer Z, Ho L, Eichenbaum H (2010) The caudal medial entorhinal cortex: a selective role in recollection-based recognition memory J Neurosci 30:15695-15699. CrossRef

Scharfman HE, Sollas AL, Smith KL, Jackson MB, Goodman JH (2002) Structural and functional asymmetry in the normal and epileptic rat dentate gyrus. J Comp Neurol 454:424-439. CrossRef Medline

Shepherd JD, Bear MF (2011) New views of Arc, a master regulator of synaptic plasticity. Nat Neurosci 14:279-284. CrossRef Medline

Steward O, Scoville SA (1976) Cells of origin of entorhinal cortical afferents to the hippocampus and fascia dentata of the rat. J Comp Neurol 169:347370. CrossRef Medline

Suzuki WA, Miller EK, Desimone R (1997) Object and place memory in the macaque entorhinal cortex. J Neurophysiol 78:1062-1081. Medline

Tamamaki N, Nojyo Y (1995) Preservation of topography in the connections between the subiculum, field $\mathrm{CA} 1$, and the entorhinal cortex in rats. J Comp Neurol 353:379-390. CrossRef Medline

Thompson CL, Pathak SD, Jeromin A, Ng LL, MacPherson CR, Mortrud MT, Cusick A, Riley ZL, Sunkin SM, Bernard A, Puchalski RB, Gage FH, Jones AR, Bajic VB, Hawrylycz MJ, Lein ES (2008) Genomic anatomy of the hippocampus. Neuron 60:1010-1021. CrossRef Medline

Thompson LT, Moyer JR Jr, Disterhoft JF (1996) Transient changes in excitability of rabbit CA3 neurons with a time course appropriate to support memory consolidation. J Neurophysiol 76:1836-1849. Medline

Vazdarjanova A, Guzowski JF (2004) Differences in hippocampal neuronal population responses to modifications of an environmental context: evidence for distinct, yet complementary, functions of CA3 and CA1 ensembles. J Neurosci 24:6489-6496. CrossRef Medline

Vazdarjanova A, Ramirez-Amaya V, Insel N, Plummer TK, Rosi S, Chowdhury S, Mikhael D, Worley PF, Guzowski JF, Barnes CA (2006) Spatial exploration induces ARC, a plasticity-related immediate-early gene, only in calcium/calmodulin-dependent protein kinase II-positive principal excitatory and inhibitory neurons of the rat forebrain. J Comp Neurol 498: 317-329. CrossRef Medline

West MJ (1999) Stereological methods for estimating the total number of neurons and synapses: issues of precision and bias. Trends Neurosci 22: 51-61. CrossRef Medline

Witter MP (2007) Intrinsic and extrinsic wiring of CA3: indications for connectional heterogeneity. Learn Mem 14:705-713. CrossRef Medline

Witter MP, Amaral DG (1991) Entorhinal cortex of the monkey: V. Projections to the dentate gyrus, hippocampus, and subicular complex. J Comp Neurol 307:437-459. CrossRef Medline 
Witter MP, Van Hoesen GW, Amaral DG (1989) Topographical organization of the entorhinal projection to the dentate gyrus of the monkey. J Neurosci 9:216-228. Medline
Young BJ, Otto T, Fox GD, Eichenbaum H (1997) Memory representation within the parahippocampal region. J Neurosci 17:5183-5195. Medline 